\title{
Marine derived biosurfactants: a vast potential future resource
}

\author{
Lakshmi Tripathi • Victor U. Irorere • Roger Marchant • Ibrahim M. Banat (D)
}

Received: 26 June 2018/Accepted: 21 August 2018/Published online: 25 August 2018

(C) The Author(s) 2018

\begin{abstract}
Surfactants and emulsifiers are surfaceactive compounds (SACs) which play an important role in various industrial processes and products due to their interfacial properties. Many of the chemical surfactants in use today are produced from nonrenewable petrochemical feedstocks, while biosurfactants (BS) produced by microorganisms from renewable feedstocks are considered viable alternatives to petroleum based surfactants, due to their biodegradability and eco-friendly nature. However, some wellcharacterised BS producers are pathogenic and therefore, not appropriate for scaled-up production. Marine-derived BS have been found to be produced by non-pathogenic organisms making them attractive possibilities for exploitation in commercial products. Additionally, BS produced from marine bacteria may show excellent activity at extreme conditions (temperature, $\mathrm{pH}$ and salinity). Despite being non-pathogenic, marine-derived BS have not been exploited commercially due to their low yields, insufficient structural elucidation and uncharacterised genes. Therefore, optimization of BS production conditions in marine bacteria, characterization of the compounds produced as well as the genes involved in the
\end{abstract}

L. Tripathi · V. U. Irorere - R. Marchant .

I. M. Banat $(\bowtie)$

School of Biomedical Sciences, Faculty of Life and

Health Sciences, Ulster University, Coleraine BT52 1SA,

UK

e-mail: im.banat@ulster.ac.uk biosynthesis are necessary to improve cost-efficiency and realise the industrial demands of SACs.

Keywords Surface-active - Marine bacteria . Biosurfactant · Emulsifier - Bioremediation · Biodegradable

\section{Surfactant industry and problem identification}

Surfactants are utilized in various bulk commercial products particularly in personal care products and household cleaners. To fulfil their worldwide demand, millions of tonnes of surfactants are annually produced from non-renewable sources such as petrochemicals. Consumption of surfactants is probably greater than 13 million tonnes per year worldwide (Marchant and Banat 2012a). The most widely used synthetic surfactants such as alkyl benzene sulfonates (ABS), are not readily biodegradable thus causing adverse effects on the environment. U.S. detergent manufacturers therefore, replaced ABS with linear alkylbenzene sulfonate (LAS) which showed no adverse impact on the environment and had the same cleaning characteristics (Cowan-Ellsberry et al. 2014). However, diminishing petrochemical stocks have created a drive towards identification of novel renewable bioresources for efficient surfactant production (Foley et al. 2012). In recent years researchers have 
been involved in continued environmental research to source replacements for synthetic surfactants and other bioactives from the marine environment (Kalogerakis et al. 2015). Surface-active compounds (SACs) produced by microorganisms offer an ideal sustainable substitute for petrochemical based surfactants. Biologically produced SACs have numerous potential applications in a wide variety of industrial sectors, due to their synthesis from waste and renewable substrates such as, hydrocarbon wastes, crude oil and vegetable oils in addition to being bio-compatible, non-toxic and biodegradable (Banat et al. 2010). They are usually classified based on their molecular weight, those surfactant molecules with low molecular weights are known as biosurfactants (BS) whilst those with high molecular weights are known as bioemulsifiers (BE).

BS are further categorized based upon their molecular structure e.g., glycolipids, lipopeptides, phospholipids, lipoprotein, fatty acids and polymeric BS. They also have a range of different properties such as, surface tension reduction, emulsification, foaming and wetting (Banat et al. 2014; Marchant and Banat 2012a). With over 5.73 million tonnes of oil spills in the oceans worldwide between 1970 and 2016 (ITOPF 2017), there is an urgent demand for novel bioactive compounds for bioremediation. BS naturally play a major role in bioremediation following oil spills and act as efficient dispersing agents facilitating microbial biodegradation (De Almeida et al. 2016; Franzetti et al. 2010). Despite their versatile properties, a higher production cost compared to chemical surfactants and the pathogenicity of some BS producing strains, remain a major obstacles for their large-scale production (Irorere et al. 2018) and the search for nonpathogenic strains remain an important research area (Elshikh et al. 2017; Funston et al. 2016). Therefore, an important question to address before they can achieve widespread application is "can we develop a cost-effective and ecologically benign process for BS production?"

\section{Surfactant production in marine bacteria}

Surfactants with diverse properties and low production costs are required to increase the applications of natural SACs, which gives greater incentive to develop surfactants of biological origin produced by microorganisms. Marine microorganisms are ubiquitous in the marine environment as well as extreme environments. The oceans have a relatively narrow range of $\mathrm{pH}$, salinity and temperature while areas such as the volcanic vents face extreme conditions. These microorganisms are known to be metabolically and physiologically adapted to survive under extreme temperature, pressure, $\mathrm{pH}$ and salinity conditions (Das et al. 2010; Thavasi et al. 2014). For example, members of the Alcanivorax genus survive at low to mild hydrostatic pressure in hydrocarbon contaminated environments. The strains A. borkumensis SK2 and A. dieselolei KS 293 have developed different strategies to cope with environmental stress under high pressure. While the respiration and cell integrity is not affected in KS 293 at mild hydrostatic pressure, SK2 activates the production of the osmolyte ectoine to cope with hydrostatic pressure (Scoma et al. 2016a, b). Marine bacteria secrete large molecules known as exopolysaccharides (EPS) consisting of proteins, polysaccharides, lipids, nucleic acids and uronic acids. EPS enhances the survival of microbial cells under changing environmental conditions through various mechanisms such as, biofilm formation, enhancing substrate adhesion, protection against limited nutrient availability, detoxification of metals and the presence of antibiotics (Harimawan and Ting 2016; Pal and Paul 2008).

Some microorganisms specifically produce amphiphilic EPS, particularly BS as a mechanism to increase the bioavailability of hydrophobic substrates such as hydrocarbons, these BS enhance the growth of indigenous bacteria capable of degrading aliphatic and aromatic hydrocarbons. BS produced from marine bacteria can facilitate hydrocarbon dispersion, degradation, emulsification and bioavailability (Das et al. 2010; Mapelli and Scoma 2017). BS from coldadapted marine microorganisms or psychrophilic organisms can work efficiently at cold and freezing temperatures, and are therefore suitable in laundry detergent formulations where low temperature washing conditions have become a priority for energy conservation (Perfumo et al. 2018; Marchant and Banat 2012b). The potential uses of BS are further improved by their low-toxicity, meaning they are applicable for large-scale industrial production and subsequent environmental disposal where they can be readily biodegraded (Irorere et al. 2017; Uzoigwe et al. 2015). Hence marine bacteria offer an excellent 
opportunity for the discovery of new SAC molecules with distinctive properties. Although highly attractive, the biosynthesis of BS from marine organisms has largely been overlooked. The mechanism of their regulation during synthesis is also not fully understood adding further difficulties to the process for their production. Several approaches are required before the widespread application of marine-derived BS can be achieved: (i) Isolation and identification of novel, nonpathogenic marine BS producing bacteria (ii) Optimization of culture conditions to achieve sufficient yields of BS and (iii) Characterization of genes involved in BS production from marine organisms. These will allow the use of marine strains in large scale BS production processes while improving yield and cost-efficiency of BS production.

Isolation of BS producing marine strains

Much of the research on BS is focused on soil isolates, including the Pseudomonas and Bacillus groups, however, BS production by marine microorganisms is an area relatively unexplored since it is still considered that marine microorganisms are difficult to culture in the laboratory (Stein et al. 1996; Walsh and Duffy 2013). The global demand for BS has led to a number of academic research groups and manufacturers searching underexploited sources such as bacteria isolated from the marine environment. Recent reports have shown the successful isolation and culture of diverse BS producing microorganisms from marine habitats (Thavasi et al. 2009). BS production is induced in most marine bacteria in the hydrocarbon polluted environment. Marine bacteria increase hydrocarbon bioavailability by the production of BS which shows surface/emulsification activities and facilitates hydrocarbon degradation (Thavasi et al. 2011). The marine oil spill from deep water horizon in the Gulf of Mexico caused large volumes of oil spill into the water. Several BS producing marine bacteria became predominant following the spill, including $A l$ teromonas, Halomonas, Alcanivorax, Colwellia, Cycloclasticus and Pseudoalteromonas (Mapelli and Scoma 2017). A number of other bacteria producing BS including, Pseudomonas, Bacillus, and Acinetobacter were reported in oil contaminated waters worldwide (Gerard et al. 1997; Hentati et al. 2016; Ortega-de la Rosa et al. 2018), although these species are not necessarily restricted to the marine environment.

The populations of marine bacteria can be increased by the addition of inorganic nutrients which allows them to use hydrocarbons as a carbon and energy source. A. borkumensis is found in low numbers in unpolluted environments but becomes the dominant microbe in hydrocarbon polluted ocean and coastal waters. The growth and multiplication of Alcanivorax in oil treated sea water increased up to $91 \%$ within 1-2 weeks of nutrient supplementation (Syutsubo et al. 2001). It was observed that addition of inorganic nutrients improved the dynamics of the bacterial community (Roling et al. 2002). Providing suitable conditions for the hydrocarbon utilization can be an efficient method to achieve growth and multiplication of these organisms. In microcosm and field biodegradation experiments, bacteria with $16 \mathrm{~S}$ rRNA sequences related to A. borkumensis and Pseudomonas stutzeri increased when supplemented with oil and inorganic nutrients (Roling et al. 2004).

Considering that the marine environment contains diverse marine microbes numbering approximately $3 \times 10^{28}$ bacteria (Copley 2002), metagenomic-based approaches can be applied for the discovery of novel marine microbial derived BS (Kennedy et al. 2011). Metagenomic analyses involve both sequence-based and function-based strategies. Function-based strategies are used to screen metagenomics libraries constructed from marine ecosystems which typically involves using Escherichia coli as the heterologous host and the subsequent screening of this library. Sequence-based analyses, involves the identification of genes based upon homology with well characterized genes that are found in sequence databases (e.g., BLAST, MEGAN, KEGG). However, the major bottleneck for identifying genes from metagenomic sources is the identification of coding regions that do not have homology in the sequence databases. Additionally, the metagenomic approach requires a deeper knowledge of the diversity of BS molecules produced and the underlying genetic systems than we have at present.

Culture conditions for production of BS from marine bacteria

The quality and productivity of BS are determined by the bacterial strain and their growth conditions. The 
optimization of growth conditions is important for the maximum production of $\mathrm{BS}$. The composition and productivity of $\mathrm{BS}$ are also influenced by carbon source, $\mathrm{pH}$, temperature, salinity, nitrogen and agitation amongst other factors. Marine microorganisms which require salts for growth are referred to as halophiles. Many marine organisms such as moderate halophiles require 3-15\% (w/v) $\mathrm{NaCl}$ for optimal growth while extreme halophiles grow optimally at 25\% (w/v) NaCl (Margesin and Schinner 2001). Halomonas are known to produce different types of glycolipids and glycoproteins with superior emulsifying activity than commercial emulsifiers. These halophilic bacteria may play a vital role for the production of surfactants and emulsifiers in oilpolluted saline environments. The growth of bacteria is influenced by salt concentration which also affects BS production. The growth of halophilic bacteria at high salt concentration can reduce the contamination risks which can significantly reduce upstream fermentation costs of BS production (Pepi et al. 2005; Tan et al. 2011). However, for large scale industrial production growth media containing high salt concentration would be regarded as undesirable due to the corrosive effects it would have on the production plant infra structure.

Different carbon sources in the growth medium influence the composition of BS production. Carbon sources studied for BS production include crude oil, diesel, glucose, sucrose and glycerol. Several studies show that marine bacteria can utilize hydrocarbons as substrate and produce BS, therefore the ability of hydrocarbon degrading marine bacteria to produce BS could be utilized in the bioremediation of hydrocarbon-contaminated environments. Halomonas sp. strain C2SS100 degraded hydrocarbons and produced BS at high salinity (Mnif et al. 2009), while Brevibacterium luteolum synthesized BS using mineral oil as a carbon source (Vilela et al. 2014). A Brevibacillus strain degraded phenanthrene to produce BS (Reddy et al. 2010) and Alteromonas sp. 17 degraded hydrocarbons and produced BS using long chain alkane eicosane (Al-Mallah et al. 1990). Glycolipopeptide BS was also produced by Corynebacterium kutscheri using cheaper carbon sources like waste motor lubricant oil and peanut oil cake (Thavasi et al. 2007). It is important to bear in mind that for large-scale commercial production of $\mathrm{BS}$ the cost of the growth medium may only constitute a smaller contribution to the total production costs when the energy required to run the fermentation for a prolonged period is taken into account and since many renewable plant oils are relatively cheap, readily available and of consistent composition. Therefore, the obsessive search for 'waste' materials as substrates towards achieving cost effective processes may be unjustified.

Nitrogen is vital for microbial growth and BS production. The type and concentration of the nitrogen source plays an essential role in the optimization of BS production (Davis et al. 1999). Different nitrogen sources could be used for the production of BS including, yeast extract, urea, peptone, ammonium sulphate, ammonium nitrate and sodium nitrate. Yeast extract was the best nitrogen source for the production of the BS in the marine Streptomyces species B3 (Khopade et al. 2012b). Sodium nitrate and yeast extract were preferred nitrogen sources for BS production by marine $B$. subtilis N3-4P (Zhu et al. 2016) while the maximum BS production was observed with phenyl alanine as the nitrogen source in marine Nocardiopsis B4 (Khopade et al. 2012a).

Another important parameter is temperature that greatly influences cell growth and BS production. BS from thermophilic microorganisms are industrially preferred due to their thermostability at temperatures above $40{ }^{\circ} \mathrm{C}$, however BS produced from mesophiles also have high levels of thermo-stability and psychrophilic marine bacteria capable of producing BS have potential applications for bioremediation in cold environments. The hydrocarbon-degrading bacterium, Rhodococcus sp. obtained from the Norwegian coastline produced BS during cultivation at $20^{\circ} \mathrm{C}$ with kerosene, $n$-hexadecane or rapeseed oil as a carbon source (Dang et al. 2016). The results reported above clearly indicate that conditions for growth and BS production are often organism specific and each organism isolated will need to be fully investigated to optimise both medium and production conditions.

Characterization of BS production in marine bacteria

The identification of possible genes involved during BS synthesis is necessary in order to understand BS synthesis and develop robust BS producing strains with high production capacity. The most well-characterized low-molecular weight BS is rhamnolipid, produced by several species of Pseudomonads and 
Burkholderia. The genes $r h l A, r h l B$ and $r h l C$, which are responsible for the biosynthesis of rhamnolipids have been found in $P$. aeruginosa as well as nonpathogenic $B$. thailandensis. These three genes are localized within a single gene cluster in Burkholderia while, the $r h l C$ gene is located at two different, remote position within the $P$. aeruginosa genome (Dubeau et al. 2009; Perfumo et al. 2013). Recently, homologues to $P$. aeruginosa rhamnolipid genes rhlA and $r h l B$ were identified in a non-pathogenic marine Pseudomonas species MCTG214(3b1) (Twigg et al. 2018). Most of the genetic studies of BS production are limited to well-characterised BS molecules, but the expression of genes involved in BS synthesis is not well studied in marine bacteria.

The genes and regulatory pathways are not necessarily identical in different BS producers. Different species can produce a BS with totally different chemical structure and even small variations in the congener composition of a surfactant can greatly affect its functional property. To fully understand how SAC synthesis is regulated in these marine strains, it is important to characterise the chemical structure and necessary genes required for BS synthesis. The chemical composition of the SAC molecules can be determined by electrospray ionization mass spectrometry (ESI-MS), high performance liquid chromatography mass spectrometry (HPLC-MS) and nuclear magnetic resonance (NMR) techniques (Smyth et al. 2010).

Few reports have been published regarding BS synthesis during hydrocarbon degradation in marine bacteria. It was reported that $P$. aeruginosa JP-11 isolated from the marine environment utilized $98.8 \% \pm 2.3 \%$ of biphenyl within $72 \mathrm{~h}$ from contaminated sites. Although $P$. aeruginosa cannot be considered a true marine bacterium, it is a common organism isolated from the marine environment. The production of BS was confirmed by the expression of the rhamnolipid synthesizing genes $\operatorname{rhlAB}$ (Chakraborty and Das 2016). Bacillus species are known to produce BS such as lichenysin, surfactin, fengycin, pumilacidin, iturin and bacillomycin (Vater et al. 2002). BS production was seen during anthracene degradation by a marine alkaliphile Bacillus licheniformis (MTCC 5514). The strain degraded $>95 \%$ of $300 \mathrm{ppm}$ anthracene and showed tolerance up to $500 \mathrm{ppm}$ of anthracene concentration. The gene involved in the BS lichenysin production was licA3, followed by degradation through the catabolic degradative enzyme, catechol 2,3 dioxygenase(C23O) (Swaathy et al. 2014).

Acinetobacter species are also known to produce high-molecular weight emulsifiers (Ortega-de la Rosa et al. 2018). In Acinetobacter lwoffii RAG-1, the genes encoding the biosynthesis of emulsan (a polysaccharide $\mathrm{BE}$ ) were reported to be clustered within a 27-kbp region termed, wee cluster (Nakar and Gutnick 2001). The bioemulsan alasan produced by $A$. radioresistens is a complex mixture of anionic polysaccharides and protein. The $\operatorname{aln} A$ gene which codes for the surfaceactive protein of alasan was cloned, sequenced, and expressed in E. coli. Significant sequence similarity (21\%) between the recombinant emulsifier protein AlnA of A. radioresistens and OmpA of E. coli was seen. However, no emulsifying or hydrocarbon solubilizing activities have been observed with $E$. coli OmpA (Toren et al. 2002). It has also been reported that the marine hydrocarbonoclastic bacterium $\mathrm{Al}$ canivorax borkumensis synthesizes glycolipids for hydrocarbon degradation (Abraham et al. 1998; Yakimov et al. 1998). The genome sequence of $A$. borkumensis SK2 revealed its capacity for BS production. The glycosyltransferase (ABO_1783) similar to RhlB from $P$. aeruginosa and glycosyltransferase protein family 9 (ABO_2215) were found to be potentially involved in BS production. The A. borkumensis SK2 genome encodes other proteins involved in emulsifier production namely, OmpA (ABO_0822), OprG/OmpW (ABO_1922) and OmpH (ABO_1152) (Schneiker et al. 2006). Similarly, genes involved in BS production were reported in the marine bacterium Achromobacter sp. HZ01. The genome of strain HZ01 harbours OmpH (gene_1336) and OmpA (gene_2469) which are both related to emulsifier production (Hong et al. 2017). Similar genes involved in biosynthesis of BS were found in the genome of Cobetia sp. MM1IDA2H-1 (Ibacache-Quiroga et al. 2017). A significant problem in using genetic information from one organism to another is the lack of sequence homology between genes which may lead to the production of similar products. The rhamnolipid production genes in $P$. aeruginosa PAO1 and $B$. thailandensis have only about $50 \%$ sequence homology (Dubeau et al. 2009). While in a marine Pseudomonas species MCTG214(3b1), unrelated to $P$. aeruginosa, which produces di-rhamnolipids identical in structure to $P$. aeruginosa, the $r h l A$ and $r h l B$ 
genes have very high sequence homology while it has so far been impossible to find an rhlC homologue which indicates the presence of second novel rhamnosyltransferase (Twigg et al. 2018). This suggests that it will be necessary to search for specific domains within the genes rather than whole gene sequences when investigating such capabilities.

\section{Marine-derived BS in bioremediation}

The release of petroleum hydrocarbons in marine environments due to oil spill and chronic pollution is a serious major concern. Chemical dispersants are effectively utilized worldwide to minimize oil spill damage. Dispersants are mixtures of one or more surfactants and solvents that enhance dispersion of oil into droplets leading to increased mobility and bioavailability of hydrocarbons. The dispersed oils are solubilized in water and degraded by microorganisms. However, chemical dispersants are toxic to aquatic species and replacing them with biological non-toxic alternatives would be very advantageous and highly sought after. Various marine $\gamma$-proteobacteria are known to secrete cell surface amphiphilic substances (BS or BE) that allow the solubilization of aromatic hydrocarbons. During growth on hydrocarbons, microbial cells attach to oil droplets by secreting BS to increase the bioavailability of hydrocarbons. BS production by these bacteria increases dispersion of hydrocarbons thereby enhancing their degradation by non-BS-producing microorganisms (McGenity et al. 2012; Perfumo et al. 2010).

Marine microorganisms such as Halomonas, Marinobacter, Myroides as well as the tropical marine yeast Yarrowia lipolytica can play an important role in the ultimate removal of hydrocarbon compounds from contaminated sites by the production of BE. Due to their diverse structural and functional property, these $\mathrm{BE}$ have potential applications in bioremediation processes (Table 1). The Halomonas sp. participate in the removal of spilled oil by synthesizing surfaceactive emulsifiers. Glycolipid molecules produced by Halomonas sp. on their cell surface enhance the solubility of hydrocarbon, and thus increase their bioavailability for degradation. The emulsifying BS produced by Halomonas sp. could be used for enhanced oil recovery processes in extreme environments (Dhasayan et al. 2014), since the emulsifier produced by this bacterium at low temperature could enhance the bioavailability of hydrocarbons in cold environments (Pepi et al. 2005).

Ornithine lipids, another type of BE produced by Myroides sp. SM1 have strong emulsification ability for crude oil and stability in a wide range of temperatures and $\mathrm{pH}$. It was reported to show better surface activity than synthetic detergents and surfactin (Maneerat et al. 2006). Emulsan, the most powerful emulsion stabilizer produced by Acinetobacter calcoaceticus RAG-1 was reported to have potential applications in microbial enhanced oil recovery (MEOR) and cleaning oil spills (Belsky et al. 1979; Rosenberg et al. 1979). Other biosurfactants have also been reported to enhance oil/hydrocarbon bioremediation activity (Banat et al. 2000; Franzetti et al. 2011) The bioemulsifier produced by Alteromonas sp. 17 (now known as Marinobacter) could also be used for the efficient degradation of hydrocarbons (Al-Mallah et al. 1990). In another report, a Marinobacter species produced a phospholipopeptide class of BS capable of emulsification. The emulsions showed low ecotoxicity and were able to disperse crude oil in artificial marine water suggesting their application for bioremediation purposes (Raddadi et al. 2017). The glycolipid BS produced from Marinobacter hydrocarbonoclasticus strain SdK644 showed twofold greater solubilisation of crude oil than tween 80 hence showing potential in marine based bioremediation (Zenati et al. 2018). Another emulsifier "Yansan" produced by Yarrowia lipolytica, an aerobic yeast showed high emulsification activity and stability over a $\mathrm{pH}$ range of 3-9 and potential applications in the formulation of perfluorocarbon (PFC) based emulsions and degradation of hydrocarbons (Amaral et al. 2006). Biosurfactants produced by Candida lipolytica yeast strain was also used formulating a commercial related product for oil bioremediation (Santos et al. 2017).

\section{Marine-derived BS as antimicrobial and therapeutic agents}

The indiscriminate use of antibiotics leading to drug resistance among pathogenic organisms is responsible for the rise of many life threatening diseases. Marine bacteria produce BS under fluctuating oceanic conditions such as oil-contaminated waters as well as secondary metabolites for their defence and survival 


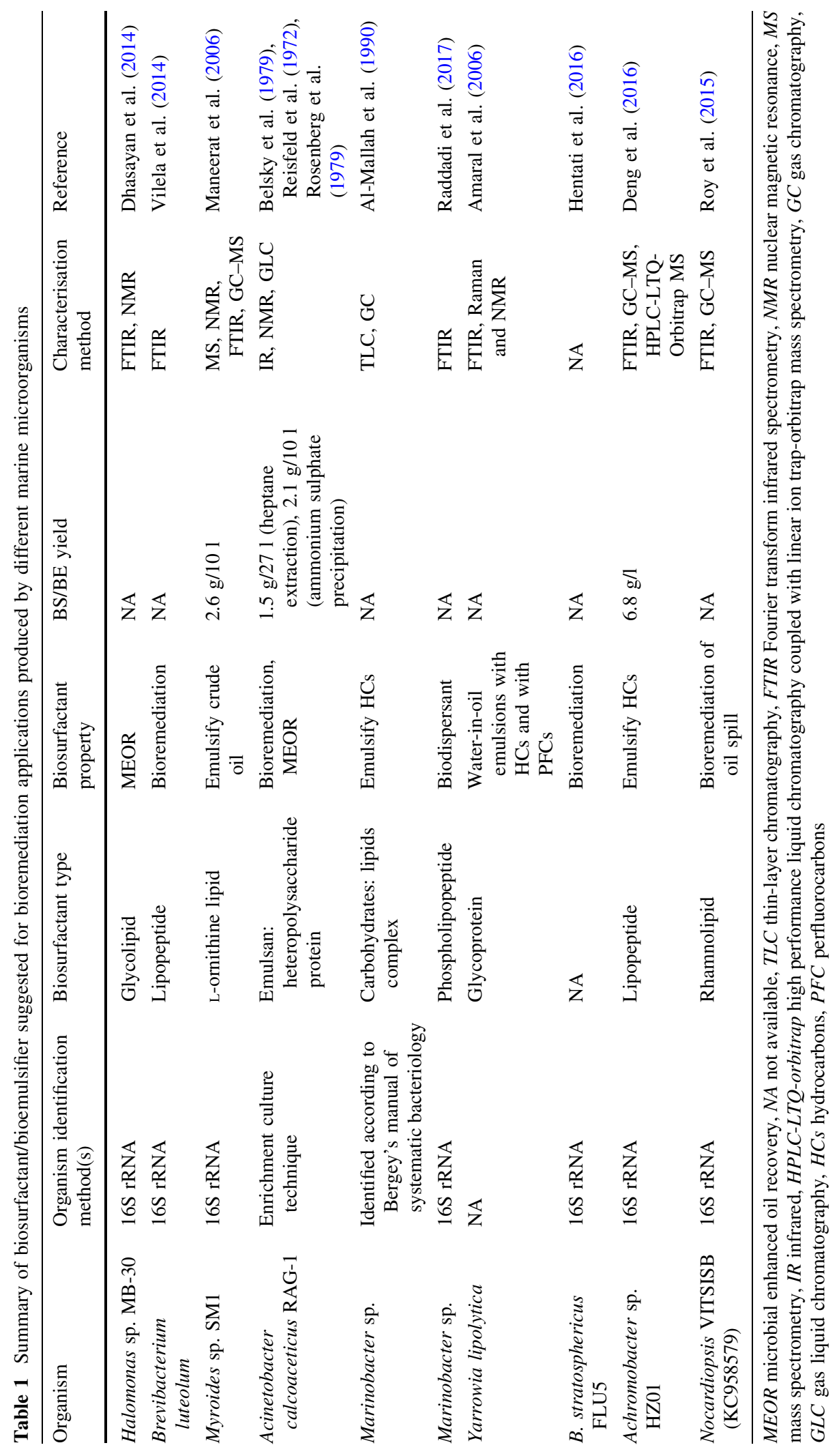


against other micro-organisms. BS derived from the marine environment have been reported to inhibit cell adhesion and biofilm formation (Das et al. 2009a; Kiran et al. 2010a). They effectively show antimicrobial, anti-adhesive and biofilm disrupting activities against pathogenic micro-organisms. In addition, some have been found to display anti-tumour/anticancer activity and, as a result can be a potential source for future drugs (Table 2). Marine derived glycolipid BS show potential for the development of novel antibiofilm drugs. For instance, the marine actinobacterium Brevibacterium casei MSA19 produces glycolipid BS which significantly disrupts the biofilm formation in both mixed culture and individual strains at $30 \mu \mathrm{g}$ glycolipid/ml (Kiran et al. 2010a). Another glycolipid BS from a marine Staphylococcus saprophyticus SBPS 15 showed antimicrobial activity against different human pathogenic clinical isolates. The BS was stable at a broad range of $\mathrm{pH}$ (3-9) and temperature (up to $80^{\circ} \mathrm{C}$ ) (Mani et al. 2016).

The biological activities of lipopeptides have been reported in marine bacteria. Marine derived lipopeptide, surfactin from B. circulans DMS-2 has potential antitumor activity against cancer cell lines HCT-15 $\left(\mathrm{IC}_{50} 80 \mu \mathrm{g} \mathrm{ml}^{-1}\right.$ ) and HT-29 (IC $50120 \mu \mathrm{g} \mathrm{ml}^{-1}$ ) (Sivapathasekaran et al. 2010). The lipopeptide BS produced by the marine $B$. circulans has anti-adhesive activity against several potential pathogenic strains. It was seen that BS-mediated surface conditioning significantly decreased bacterial adhesion of pathogenic strains like E. coli, Micrococcus flavus and Proteus vulgaris up to $89 \%$ at a concentration as low as $0.1 \mathrm{~g} / \mathrm{l}$ showing its potential in biomedical applications (Das et al. 2009a). In another study a marinederived $B$. subtilis SDNS produced $\varepsilon$-poly-L-lysine ( $\varepsilon$ PL) which showed anti-cancer activity against human Hela S3 cell line (El-Sersy et al. 2012).

The molecular structure of a particular lipopeptide variant defines its biological activity. For example, the length of carbon-chain affects the antifungal activity in iturinic lipopeptides. Due to their hydrophobic nature the longer fatty acid chain interact effectively with the cell membrane. As reported, among three different lipopeptides isolated from marine derived $B$. mojavensis, the antifungal activity of fengycins $\left(\mathrm{C}_{16}\right.$ and $\left.\mathrm{C}_{17}\right)$ were stronger than mojavensin $\mathrm{A}\left(\mathrm{C}_{15}\right)(\mathrm{Ma}$ and $\mathrm{Hu}$ 2014; Ma et al. 2012). Likewise, the longer fatty acid chain isoform $\mathrm{C}_{16}$ of iturin A from marine Bacillus megaterium inhibited the proliferation of tumour cells by disrupting the Akt pathway leading to apoptosis (Dey et al. 2015). In another report, fengycin fractions produced by $B$. circulans strain, where out of four different fractions, antimicrobial activity was observed only with variants of $\mathrm{C}_{16}$ and $\mathrm{C}_{17}$ (Sivapathasekaran et al. 2009). The longer fatty acid chain of BS may offer advantages in increasing the surfaceactivity of these molecules.

These properties suggest that marine-derived BS can serve as a source of new biomolecules for the discovery of novel drugs. Other possible applications of BS can be the synthesis of metallic nanoparticles using marine-derived surfactants. Metallic nanoparticles are receiving great interest in the field of biomedicine for example, tissue engineering, drug delivery, detection of pathogens, detection of tumours, biological markers etc. (Salata 2004). Recently BS have been used both in nanoparticle synthesis and stabilization (Plaza et al. 2014). Microorganisms have developed the capability to grow and survive at high metal concentrations by various mechanisms such as, impermeable cell membrane, efflux of toxic ions, oxidation or reduction of ions and production of EPS (Decho 1990). Marine bacteria can bind a wide range of heavy metals through production of BS and contribute to organic carbon cycling (Das et al. 2009b). Therefore, utilization of marine derived BS is a safer route for environmental friendly synthesis of nanoparticles. In a study, a glycolipid BS was synthesized from sponge-associated marine Brevibacterium casei MSA19 under solid state fermentation. The glycolipid helped in stabilization of nanoparticles and prevented aggregation (Kiran et al. 2010b). Biosynthesis of metallic nanoparticles using bacteria and fungi has gained more attention while, synthesis of metallic nanoparticles using marine bacteria is an area yet to be fully explored (Plaza et al. 2014).

\section{Marine-derived BS in food and cosmetic formulations}

Due to increased use of stabilizing and thickening agents in food products, these industries are looking for ingredients which can improve food quality and properties. Gum arabic, xanthan gum and lecithin are widely used hydrocolloid emulsifiers which efficiently emulsify and stabilize oil-in-water emulsions. In Quorn products (quorn.co.uk), dried fungus culture 


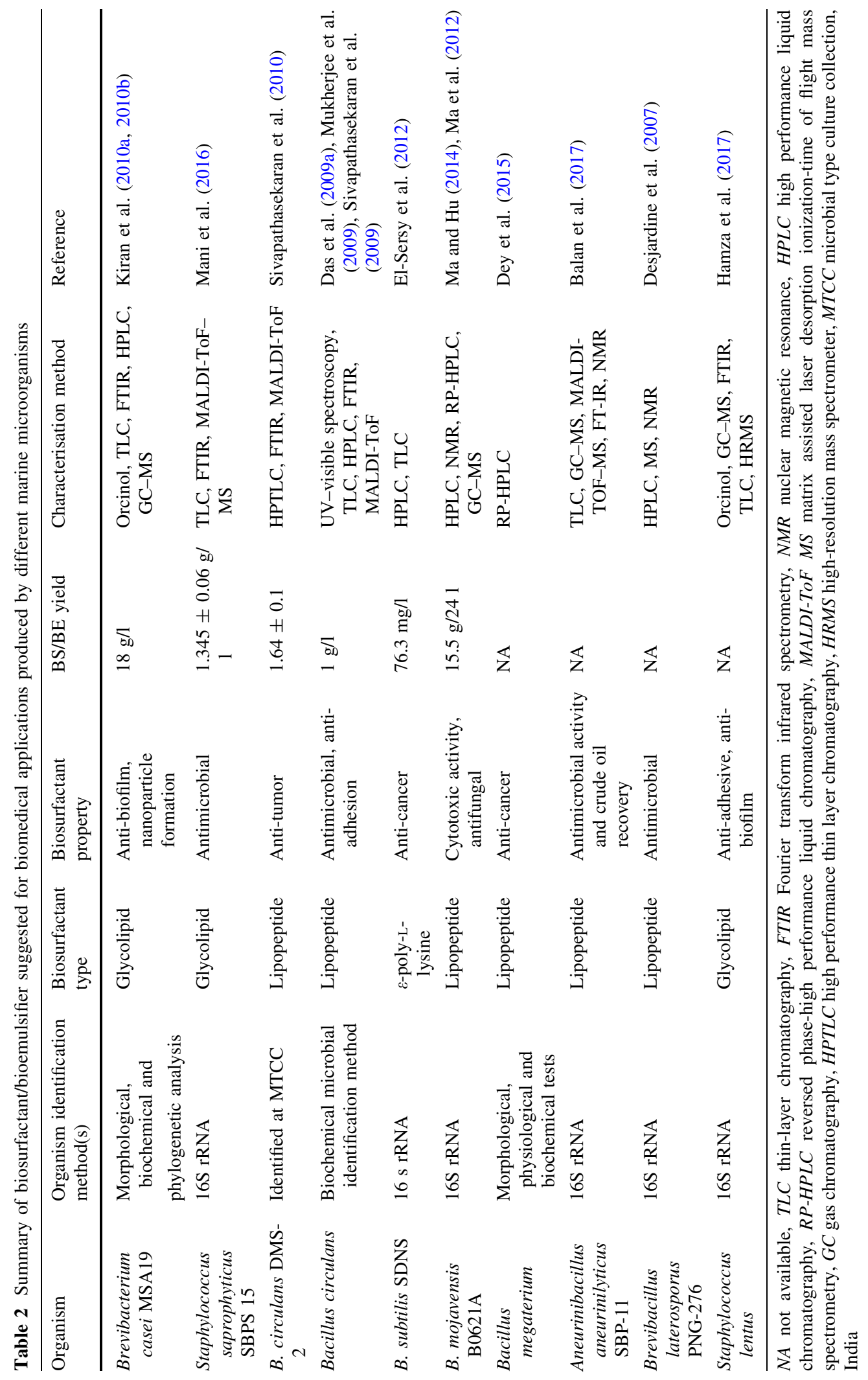


from Fusarium venenatum is used together with egg albumen as a binder. While, in vegan food products, potato protein is added in place of egg albumen. However, climate change and weather fluctuations such as drought will produce defoliation and affect the production of plant based gums. In order, to reduce the dependency on synthetic emulsifiers and plant based emulsifiers there is increased interest in finding new ingredients. Contrary to chemical surfactants, marine derived BS are non-toxic and/or less toxic with high stability at extreme temperature, $\mathrm{pH}$ and salinity.

Not many studies on the applications of marinederived BS in food and cosmetic formulations have been reported so far. The only commercialized microbial emulsifier is Emulsan produced from $A$. calcoaceticus. BS, which due to its emulsion stabilizing property, can improve consistency, texture and solubilisation of fat globules, and aroma in food products. Incorporation of $\mathrm{BE}$ has been found to improve the rheology of dough, increasing the volume and emulsification of fat and thus finds useful applications in the bakery and meat processing industries. For example, a glycoprotein emulsion stabilizer produced by marine Antarctobacter sp. TG22 can produce stable oil-in-water emulsions with commercial food-grade oils (Gutierrez et al. 2007a). Similarly two other glycoprotein emulsifiers from marine Halomonas species TG39 and TG67 show superior emulsifying properties when compared to commercial emulsifiers with stable activity under acidic conditions and high temperatures (Gutierrez et al. 2007b).

The lipopeptide MSA31 from a marine Nesterenkonia species is an effective emulsifier, with good antioxidant activity and its addition to muffins improved softness and retained food quality. The lipopeptide MSA31 effectively reduced 90\% of biofilm formed by Staphylococcus aureus and was non-toxic to the brine shrimp nauplii (up to $200 \mu \mathrm{g}$ / $\mathrm{ml}$ ) (Kiran et al. 2017). Another bioemulsifier produced by a marine bacterium Enterobacter cloacae was reported to promote the viscosity of acidic food products (Iyer et al. 2006). In the food industry, there is wide scope for marine derived-BS as emulsifiers, stabilizing agents, antimicrobial and antiadhesives/ antibiofilm agents (Table 3).

Chemicals used in cosmetic formulations often cause skin irritations and allergies. There is significant interest in natural cosmetic products among consumers. Replacement of SACs in these products with
BS can reduce such harmful effects. The surfaceactive properties are essential to determine the type and amount of BS in detergents, cosmetic, pharmaceuticals and various other industries. The type of BS compound to be incorporated in the formulations can be selected based on their emulsifying ability and/or surface-activity such as, hydrophilic-lipophilic balance (HLB) and critical micelle concentration (CMC), respectively. The HLB defines the polarity of the BS, which gives an indication of its solubility in different systems. BS with a high HLB value indicates that it is highly hydrophilic while, a low HLB value shows a high lipophilic character. Based on the HLB values, a BS will be an emulsifier, antifoaming agent and wetting agent which are desirable properties in cosmetic products.

$\mathrm{CMC}$ is the minimum concentration of $\mathrm{BS}$ required to lower the ST of water. At the CMC surfactant molecules form micelles to reduce surface tension and interfacial tension. The surface-active properties of a BS are determined by its side chain length, unsaturated bonds and the size of hydrophilic group. With increasing hydrophobicity, the CMC of BS molecules tends to decrease. That means, a lower concentration of BS is required for micelle formation. It is reported, Burkholderia thailandensis producing rhamnolipids Rha-Rha- $\mathrm{C}_{14}-\mathrm{C}_{14}$ has a CMC of $225 \mathrm{mg} \mathrm{l}^{-1}$ compared to $P$. aeruginosa $\mathrm{PG} 201$ producing Rha-Rha$\mathrm{C}_{10}-\mathrm{C}_{10}$ of $600 \mathrm{mg} / \mathrm{l}$. Due to the hydrophobicity of the longer fatty acid chains, Burkholderia BS has a lower CMC compared to $P$. aeruginosa (Dubeau et al. 2009).

Considering the foaming and emulsifying properties, BS can be used for different applications in health care products including, cleansers, moisturizers, toothpaste and personal care products. Marine-derived BS effectively show antimicrobial, anti-adhesive and biofilm disrupting activities against pathogenic microorganisms. This property can be utilised in cosmetic and skin care products. Similar to skin cell membranes, the fatty acid chain in BS can prevent generation of free radicals from UV radiation. Therefore, BS can be applied as antioxidants in skin care products (Vecino et al. 2017).

Before introducing BS in industrial formulations, it is necessary to determine the toxicity of these SACs on cells or animal models. For example, the toxicity of glycolipid BS (BS-SLSZ2) produced by a marine epizootic bacterium Staphylococcus lentus towards eukaryotic model organism was determined. The 


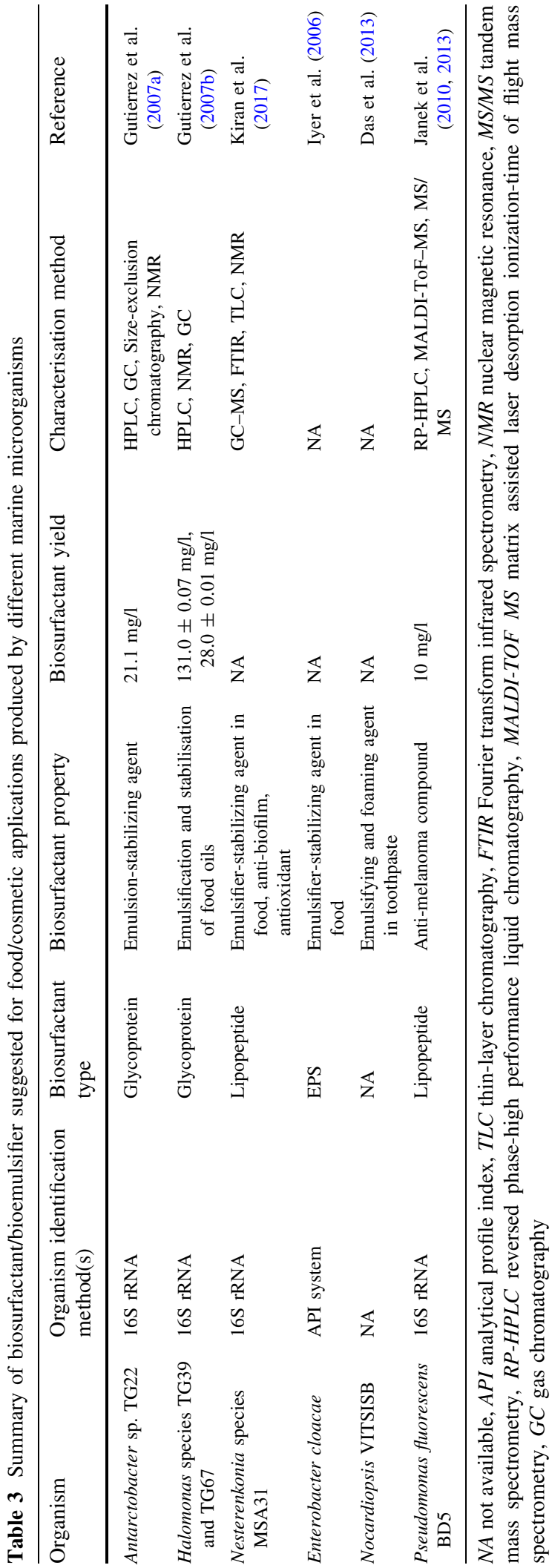

glycolipid BS-SLSZ2 efficiently inhibited biofilm formation in Vibrio harveyi and $P$. aeruginosa. In vivo experiments showed that BS-SLSZ2 was non-toxic towards Artemia salina and was effective in protecting A. salina against $V$. harveyi and $P$. aeruginosa infections (Hamza et al. 2017). In another report, marine Pseudomonas sp. MK90e8 and MK91CC8 was reported to produce massetolide $\mathrm{A}$, novel cyclic depsipeptide and viscosin, repsectively. Massetolide A and viscosin exhibited in vitro antimicrobial activity against Mycobacterium tuberculosis and Mycobacterium avium-intracellulare. The effect of massetolide A was found to be non-toxic to mice at a dose of $10 \mathrm{mg} / \mathrm{kg}$ thus showing potential in treating infections against Mycobacterium (Gerard et al. 1997).

The activity of Pseudofactin II (PFII), a lipopeptide BS isolated from the Arctic strain of P. fluorescens BD5 was compared with normal human dermal fibroblast (NHDF). PFII induced apoptosis of melanoma skin cancer cells while NHDF were less affected under same conditions. The mechanism of melanoma cell death may be due to increased plasma membrane permeability by BS micelles. The activity of PFII was most effective above CMC (130-140 $\mu \mathrm{M}$ ) (Janek et al. 2013). The toxicity of BS from marine bacteria Nocardiopsis VITSISB was evaluated in toothpaste formulation. BS was found to more efficient and less toxic surfactant compared to chemical surfactant sodium lauryl sulphate (Das et al. 2013). Further investigations should be done to supply safe and effective products to satisfy consumers' demands.

\section{Recommendation and conclusion}

Due to their interesting biological properties, BS from extremophiles have great potentials with a broad range of applications for industrial and consumer products. Considering their properties such as, emulsifiers, thickeners, anti-oxidants, extreme tolerance to $\mathrm{pH}$ or temperature as well as antifungal and antimicrobial activities we look forward to potentially new products with marine-derived BS as their surface-active ingredients. Although highly desirable they also have their disadvantages such as the production of relatively low yield of BS and high production costs. In some studies, either the product yield is very low or have not been quantified. Additionally, in some studies, the taxonomic identification of strains has not been carried out 
using reliable methods. As suggested by Irorere et al. (2017) criteria should be followed before claims for a BS producing strain and the identity of the product are made. In comparison to BS produced from mesophilic microorganisms, not much work has been done on marine BS. Fermentation optimisation by varying physiochemical factors including, temperature, $\mathrm{pH}$, aeration and agitation speed and nitrogen would be beneficial to increase the product yield. In order to develop robust BS producing strains it is important to identify the genes involved in SACs biosynthesis and to investigate the regulatory mechanisms involved in BS synthesis by targeting those regulatory genes.

Close examination of the information presented in Tables 1, 2 and 3 reveals the deficiencies in the data currently available from the published literature. Although many of the organisms have been reliably identified using 16S rRNA sequence data, other identifications have relied on morphological, physiological and biochemical tests. This lack of specific taxonomic data makes extrapolations from one study to another significantly more difficult. The other glaring lack of information concerns the yield of BS produced either as a crude yield or as a purified material. As we have already pointed out one important issue dictating whether BS will become a common constituent of consumer products or will be used in bulk bioremediations is cost. We can see from the few yield figures given that in general they are exceptionally low, of the order of $\mathrm{mg} / \mathrm{l}$, rather than $\mathrm{g} / \mathrm{l}$. In the case of one microbial biosurfactant that has reached industrial use, the sophorolipid from Starmerella bombicola, yields are of the order of hundreds of $\mathrm{g} / \mathrm{l}$. Until the production from marine organisms can be increased, either through the manipulation of the growth conditions or through genetic manipulation, there is little prospect of major commercial interest.

The final point we can take from data in the tables is the lack of consistency and reliability of the methods used to identify the products. In some instances, no real attempts have been made to specifically identify the products and in others general analytical methods have been used which only provide indicative information concerning the structures. In many of the applications under considered for BS, particularly by the pharmaceutical and cosmetic industries, specific knowledge of the compounds being produced is imperative. In many cases microbial BS are typically a mixture of different congeners and where bioactivity is being investigated it is critical that pure samples of individual congeners are used in order to be able to assign a specific bioactivity to a molecule. Mixtures of different molecules may have competing activities which may cancel each other out.

Some studies have been done on potential rhamnolipid producing strains including $P$. aeruginosa and Burkholderia species to enhance rhamnolipid production. One such approach is cloning the rhamnolipid biosynthesis genes rhlA and $r h l B$ into non-rhamnolipid producing strains, E. coli BL21 (DE3) and $P$. aeruginosa $\mathrm{PAO} 1 \mathrm{rhhlA}$. However, the BS yield from the recombinant strains was too low in comparison to the wild type strains (Wang et al. 2007). Another approach to increase the BS yield is to silence the genes competing with the BS production pathway. For example, Funston et al. (2017) knocked-out the polyhydroxyalkanoate (PHA) pathway synthesis genes for enhanced rhamnolipid production. The halophile Halomonas species are ubiquitous in marine environments and produces $\mathrm{BE}$ which effectively emulsifies hydrocarbons and other petroleum contaminants. These species are known BS producers as well as PHA producers. However, the effect of PHA deficient mutation on the yield of its SACs is not known. It might be interesting to follow a similar strategy in Halomonas species to reduce the carbon flux towards other metabolic pathways and increase the BS production.

The chemical composition and toxicity must be known before commercialisation of the SACs. The developed techniques such as high-performance liquid chromatography (HPLC) and ultra-performance liquid chromatography tandem mass spectrometry (UPLCMS/MS) can be used to analyse BS congeners (Rudden et al. 2015). The analysis and purification of a particular BS fraction displaying bioactivity is a prerequisite for subsequent biomedical applications. Reverse-phase high-performance liquid chromatography (RP-HPLC) has recently been used to fractionate and purify glycolipid and lipopeptide compounds (Sivapathasekaran et al. 2009). The separation and purification of BS can enhance the level of bioactivity of BS isoforms. The antimicrobial activity of the lipopeptide was reported to increase further after purification (Mukherjee et al. 2009). While, the toxicity of BS can be tested in eukaryotic models such as, Caenorhabditis elegans and Artemia sp. The toxicity of the BS producing strain can be tested in the 
Galleria mellonella model. The Galleria model was used to test the pathogenicity in rhamnolipid BS producing strains and it was found that $B$. thailandensis was significantly less pathogenic than $P$. aeruginosa (Irorere et al. 2018) and that a marine Pseudomonad was also non-pathogenic (Twigg et al. 2018).

Marine-derived BS effectively emulsify hydrocarbons therefore, are suitable for marine-based bioremediation. The improved biodegradation levels obtained with marine-derived BS indicate that they represent the most efficient accelerators for hydrocarbon biodegradation through increasing the bioavailability of oil. Use of extremophiles such as, Acinetobacter, Halomonas, Marinobacter which effectively produce BS and participate in marine bioremediation should be preferred over mesophilic microorganisms for remediation of oil spills. Psychrophilic bacteria are capable of degrading crude oil efficiently at low temperatures. Therefore, BS produced from psychrophilic bacteria are suitable for bioremediation of hydrocarbon contaminated sites in cold environments. For bioremediation purposes, the impurities within the BS mixture act as a co-substrate and enhance the degradation of pollutants (MataSandoval et al. 2001). Considering the downstream processing costs further purification of $\mathrm{BS}$ is not required for bioremediation purposes.

Acknowledgements The authors LT, RM and IMB acknowledge the financial support from the MARISURF Project funded by the European Union Framework Programme for Research and Innovation, Horizon 2020 under Grant Agreement No. 635340. VUI acknowledges Ulster University Vice Chancellor's Research Scholarship.

\section{Compliance with ethical standards}

Conflict of interest The authors declare that they have no conflict of interest.

Open Access This article is distributed under the terms of the Creative Commons Attribution 4.0 International License (http:// creativecommons.org/licenses/by/4.0/), which permits unrestricted use, distribution, and reproduction in any medium, provided you give appropriate credit to the original author(s) and the source, provide a link to the Creative Commons license, and indicate if changes were made.

\section{References}

Abraham WR, Meyer H, Yakimov M (1998) Novel glycine containing glucolipids from the alkane using bacterium Alcanivorax borkumensis. Biochim Biophys Acta 1393:57-62

Al-Mallah M, Goutx M, Mille G, Bertrand J-C (1990) Production of emulsifying agents during growth of a marine $\mathrm{Al}$ teromonas in sea water with eicosane as carbon source, a solid hydrocarbon. Oil Chem Pollut 6:289-305. https://doi. org/10.1016/S0269-8579(05)80005-X

Amaral PFF, da Silva JM, Lehocky M, Barros-Timmons AMV, Coelho MAZ, Marrucho IM, Coutinho JAP (2006) Production and characterization of a bioemulsifier from Yarrowia lipolytica. Process Biochem 41:1894-1898. https:// doi.org/10.1016/j.procbio.2006.03.029

Balan SS, Kumar CG, Jayalakshmi S (2017) Aneurinifactin, a new lipopeptide biosurfactant produced by a marine Aneurinibacillus aneurinilyticus SBP-11 isolated from Gulf of Mannar: purification, characterization and its biological evaluation. Microbiol Res 194:1-9. https://doi.org/ 10.1016/j.micres.2016.10.005

Banat IM, Makkar RS, Cameotra SS (2000) Potential commercial applications of microbial surfactants. Appl Microbiol Biotechnol 53(5):495-508. https://doi.org/10. 1007/s002530051648

Banat IM, Franzetti A, Gandolfi I, Giuseppina B, Martinotti MG, Fracchia L, Smyth TJ, Marchant R (2010) Microbial biosurfactants production, applications and future potential. Appl Microbiol Biotechnol 87:427-444. https://doi. org/10.1007/s00253-010-2589-0

Banat IM, Satpute SK, Cameotra SS, Patil R, Nyayanit NV (2014) Cost effective technologies and renewable substrates for biosurfactants' production. Front Microbiol 5:697. https://doi.org/10.3389/fmicb.2014.00697

Belsky I, Gutnick DL, Rosenberg E (1979) Emulsifier of Arthrobacter RAG-1: determination of emulsifier-bound fatty acids. FEBS Lett 101:175-178. https://doi.org/10. 1016/0014-5793(79)81320-4

Chakraborty J, Das S (2016) Characterization of the metabolic pathway and catabolic gene expression in biphenyl degrading marine bacterium Pseudomonas aeruginosa JP11. Chemosphere 144:1706-1714. https://doi.org/10.1016/ j.chemosphere.2015.10.059

Copley J (2002) All at sea. Nature 415:572. https://doi.org/10. $1038 / 415572 \mathrm{a}$

Cowan-Ellsberry C et al (2014) Environmental safety of the use of major surfactant classes in North America. Crit Rev Environ Sci Technol 44:1893-1993. https://doi.org/10. 1080/10739149.2013.803777

Dang NP, Landfald B, Willassen NP (2016) Biological surfaceactive compounds from marine bacteria. Environ Technol 37:1151-1158. https://doi.org/10.1080/09593330.2015. 1103784

Das P, Mukherjee S, Sen R (2009a) Antiadhesive action of a marine microbial surfactant. Colloids Surf B 71:183-186. https://doi.org/10.1016/j.colsurfb.2009.02.004

Das P, Mukherjee S, Sen R (2009b) Biosurfactant of marine origin exhibiting heavy metal remediation properties. 
Bioresour Technol 100:4887-4890. https://doi.org/10. 1016/j.biortech.2009.05.028

Das P, Mukherjee S, Sivapathasekaran C, Sen R (2010) Microbial surfactants of marine origin: potentials and prospects. Adv Exp Med Biol 672:88-101

Das I, Roy S, Chandni S, Loganathan K, Kumar G, Rao B (2013) Biosurfactant from marine actinobacteria and its application in cosmetic formulation of toothpaste. Der Pharm Lett 5:1-6

Davis DA, Lynch HC, Varley J (1999) The production of surfactin in batch culture by Bacillus subtilis ATCC 21332 is strongly influenced by the conditions of nitrogen metabolism. Enzyme Microb Technol 25:322-329. https://doi.org/ 10.1016/S0141-0229(99)00048-4

De Almeida DG, Soares Da Silva RC, Luna JM, Rufino RD, Santos VA, Banat IM, Sarubbo LA (2016) Biosurfactants: promising molecules for petroleum biotechnology advances. Front Microbiol 7:1718. https://doi.org/10.3389/ fmicb.2016.01718

Decho AW (1990) Microbial exopolymer secretions in ocean environments: their role(s) in food webs and marine processes. Oceanogr Mar Biol Ann Rev 28:73-153

Deng MC, Li J, Hong YH, Xu XM, Chen WX, Yuan JP, Peng J, Yi M, Wang JH (2016) Characterization of a novel biosurfactant produced by marine hydrocarbon-degrading bacterium Achromobacter sp. HZ01. J Appl Microbiol 120:889-899. https://doi.org/10.1111/jam.13065

Desjardine K, Pereira A, Wright H, Matainaho T, Kelly M, Andersen RJ (2007) Tauramamide, a lipopeptide antibiotic produced in culture by Brevibacillus laterosporus isolated from a marine habitat: structure elucidation and synthesis. J Nat Prod 70:1850-1853. https://doi.org/10.1021/ np070209r

Dey G, Bharti R, Dhanarajan G, Das S, Dey KK, Dumar BNP, Sen R, Mandal M (2015) Marine lipopeptide Iturin A inhibits Akt mediated GSK3beta and FoxO3a signaling and triggers apoptosis in breast cancer. Sci Rep 5:10316. https://doi.org/10.1038/srep10316

Dhasayan A, Kiran GS, Selvin J (2014) Production and characterisation of glycolipid biosurfactant by Halomonas sp. MB-30 for potential application in enhanced oil recovery. Appl Biochem Biotechnol 174:2571-2584. https://doi.org/ 10.1007/s12010-014-1209-3

Dubeau D, Deziel E, Woods DE, Lepine F (2009) Burkholderia thailandensis harbors two identical rhl gene clusters responsible for the biosynthesis of rhamnolipids. BMC Microbiol 9:263. https://doi.org/10.1186/1471-2180-9-263

El-Sersy NA, Abdelwahab AE, Abouelkhiir SS, Abou-Zeid DM, Sabry SA (2012) Antibacterial and anticancer activity of epsilon-poly-L-lysine (epsilon-PL) produced by a marine Bacillus subtilis sp. J Basic Microbiol 52:513-522. https://doi.org/10.1002/jobm.201100290

Elshikh M, Funston S, Chebbi A, Ahmed S, Marchant R, Banat IM (2017) Rhamnolipids from non-pathogenic Burkholderia thailandensis E264: Physicochemical characterization, antimicrobial and antibiofilm efficacy against oral hygiene related pathogens. N Biotechnol 36:26-36. https://doi.org/10.1016/j.nbt.2016.12.009

Foley P, Kermanshahi pour A, Beach ES, Zimmerman JB (2012) Derivation and synthesis of renewable surfactants.
Chem Soc Rev 41:1499-1518. https://doi.org/10.1039/ c1cs $15217 \mathrm{c}$

Franzetti A, Tamburini E, Banat IM (2010) Applications of biological surface active compounds in remediation technologies. Adv Exp Med Biol 672:121-134

Franzetti A, Gandolfi I, Bestetti G, Banat IM (2011) (Bio)surfactant and bioremediation, successes and failures. In: Plaza G (ed) Trends in bioremediation and phytoremediation. Research Signpost, Kerala, pp 145-156. ISBN 978-81-308-0424-8

Funston SJ, Tsaousi K, Rudden M, Smyth TJ, Stevenson PS, Marchant R, Banat IM (2016) Characterising rhamnolipid production in Burkholderia thailandensis E264, a nonpathogenic producer. Appl Microbiol Biotechnol 100:7945-7956. https://doi.org/10.1007/s00253-0167564-y

Funston SJ, Tsaousi K, Smyth TJ, Twigg MS, Marchant R, Banat IM (2017) Enhanced rhamnolipid production in Burkholderia thailandensis transposon knockout strains deficient in polyhydroxyalkanoate (PHA) synthesis. Appl Microbiol Biotechnol 101:8443-8454. https://doi.org/10. 1007/s00253-017-8540-x

Gerard J, Lloyd R, Barsby T, Haden P, Kelly MT, Andersen RJ (1997) Massetolides A-H, antimycobacterial cyclic depsipeptides produced by two Pseudomonads isolated from marine habitats. J Nat Prod 60:223-229. https://doi.org/10. 1021/np9606456

Gutierrez T, Mulloy B, Bavington C, Black K, Green DH (2007a) Partial purification and chemical characterization of a glycoprotein (putative hydrocolloid) emulsifier produced by a marine bacterium Antarctobacter. Appl Microbiol Biotechnol 76:1017-1026. https://doi.org/10. 1007/s00253-007-1091-9

Gutierrez T, Mulloy B, Black K, Green DH (2007b) Glycoprotein emulsifiers from two marine Halomonas species: chemical and physical characterization. J Appl Microbiol 103:1716-1727. https://doi.org/10.1111/j.1365-2672. 2007.03407.x

Hamza F, Satpute S, Banpurkar A, Kumar AR, Zinjarde S (2017) Biosurfactant from a marine bacterium disrupts biofilms of pathogenic bacteria in a tropical aquaculture system. FEMS Microbiol Ecol. https://doi.org/10.1093/ femsec/fix 140

Harimawan A, Ting Y-P (2016) Investigation of extracellular polymeric substances (EPS) properties of $P$. aeruginosa and $B$. subtilis and their role in bacterial adhesion. Colloids Surf B 146:459-467. https://doi.org/10.1016/j.colsurfb. 2016.06.039

Hentati D, Chebbi A, Loukil S, Kchaou S, Godon JJ, Sayadi S, Chamkha M (2016) Biodegradation of fluoranthene by a newly isolated strain of Bacillus stratosphericus from Mediterranean seawater of the Sfax fishing harbour, Tunisia. Environ Sci Pollut Res Int 23:15088-15100. https://doi.org/10.1007/s11356-016-6648-7

Hong YH et al (2017) Genome sequencing reveals the potential of Achromobacter sp. HZ01 for bioremediation. Front Microbiol 8:1507. https://doi.org/10.3389/fmicb.2017. 01507

Ibacache-Quiroga C, Canales C, Charifeh M, Dinamarca MA (2017) Genome sequence of Cobetia sp. strain MM1IDA2H-1, a hydrocarbon-degrading and biosurfactant- 
producing marine bacterium. Genome Announc. https:// doi.org/10.1128/genomea.00132-17

Irorere VU, Tripathi L, Marchant R, McClean S, Banat IM (2017) Microbial rhamnolipid production: a critical reevaluation of published data and suggested future publication criteria. Appl Microbiol Biotechnol 101:3941-3951. https://doi.org/10.1007/s00253-017-8262-0

Irorere VU, Smyth TJ, Cobice D, McClean S, Marchant R, Banat IM (2018) Fatty acid synthesis pathway provides lipid precursors for rhamnolipid biosynthesis in Burkholderia thailandensis E264. Appl Microbiol. https:// doi.org/10.1007/s00253-018-9059-5

ITOPF-International Tanker Owners Pollution Federation (2017) http://www.itopf.com. Accessed April 2017

Iyer A, Mody K, Jha B (2006) Emulsifying properties of a marine bacterial exopolysaccharide. Enzyme Microb Technol 38:220-222. https://doi.org/10.1016/j.enzmictec. 2005.06.007

Janek T, Łukaszewicz M, Rezanka T, Krasowska A (2010) Isolation and characterization of two new lipopeptide biosurfactants produced by Pseudomonas fluorescens BD5 isolated from water from the Arctic Archipelago of Svalbard. Bioresour Technol 101:6118-6123. https://doi.org/ 10.1016/j.biortech.2010.02.109

Janek T, Krasowska A, Radwanska A, Lukaszewicz M (2013) Lipopeptide biosurfactant pseudofactin II induced apoptosis of melanoma A 375 cells by specific interaction with the plasma membrane. PLoS ONE 8:e57991. https://doi. org/10.1371/journal.pone.0057991

Kalogerakis N, Arff J, Banat IM et al (2015) The role of environmental biotechnology in exploring, exploiting, monitoring, preserving, protecting and decontaminating the marine environment. N Biotechnol 32:157-167. https:// doi.org/10.1016/j.nbt.2014.03.007

Kennedy J, O'Leary ND, Kiran GS, Morrissey JP, O'Gara F, Selvin J, Dobson AD (2011) Functional metagenomic strategies for the discovery of novel enzymes and biosurfactants with biotechnological applications from marine ecosystems. J Appl Microbiol 111:787-799. https://doi. org/10.1111/j.1365-2672.2011.05106.x

Khopade A, Biao R, Liu X, Mahadik K, Zhang L, Kokare C (2012a) Production and stability studies of the biosurfactant isolated from marine Nocardiopsis sp. B4. Desalination 285:198-204. https://doi.org/10.1016/j.desal.2011

Khopade A, Ren B, Liu XY, Mahadik K, Zhang L, Kokare C (2012b) Production and characterization of biosurfactant from marine Streptomyces species B3. J Colloid Interface Sci 367:311-318. https://doi.org/10.1016/j.jcis.2011.11. 009

Kiran GS, Sabarathnam B, Selvin J (2010a) Biofilm disruption potential of a glycolipid biosurfactant from marine Brevibacterium casei. FEMS Immunol Med Microbiol 59:432-438. https://doi.org/10.1111/j.1574-695X.2010. 00698.x

Kiran GS, Sabu A, Selvin J (2010b) Synthesis of silver nanoparticles by glycolipid biosurfactant produced from marine Brevibacterium casei MSA19. J Biotechnol 148:221-225. https://doi.org/10.1016/j.jbiotec.2010.06. 012

Kiran GS, Priyadharsini S, Sajayan A, Priyadharsini GB, Poulose N, Selvin J (2017) Production of lipopeptide biosurfactant by a Marine Nesterenkonia sp and its application in food industry. Front Microbiol. https://doi.org/10. 3389/fmicb.2017.01138

Ma Z, Hu J (2014) Production and characterization of Iturinic lipopeptides as antifungal agents and biosurfactants produced by a marine pinctada martensii-derived Bacillus mojavensis B0621A. Appl Biochem Biotechnol 173:705-715. https://doi.org/10.1007/s12010-014-0879-1

Ma Z, Wang N, Hu J, Wang S (2012) Isolation and characterization of a new iturinic lipopeptide, mojavensin A produced by a marine-derived bacterium Bacillus mojavensis B0621A. J Antibiot 65:317-322. https://doi.org/10.1038/ ja.2012.19

Maneerat S, Bamba T, Harada K, Kobayashi A, Yamada H, Kawai F (2006) A novel crude oil emulsifier excreted in the culture supernatant of a marine bacterium, Myroides sp. strain SM1. Appl Microbiol Biotechnol 70:254-259. https://doi.org/10.1007/s00253-005-0050-6

Mani P, Dineshkumar G, Jayaseelan T, Deepalakshmi K, Ganesh Kumar C, Senthil Balan S (2016) Antimicrobial activities of a promising glycolipid biosurfactant from a novel marine Staphylococcus saprophyticus SBPS 153. Biotech 6:163. https://doi.org/10.1007/s13205-016-0478-7

Mapelli F, Scoma A, Michoud G, Aulenta F, Boon N, Borin S, Kalogerakis N, Daffonchio D (2017) Biotechnologies for marine oil spill cleanup: indissoluble ties with microorganisms. Trends Biotechnol 35:860-870. https://doi.org/ 10.1016/j.tibtech.2017.04.003

Marchant R, Banat IM (2012a) Microbial biosurfactants: challenges and opportunities for future exploitation. Trends Biotechnol 30:558-565. https://doi.org/10.1016/j.tibtech. 2012.07.003

Marchant R, Banat IM (2012b) Biosurfactants: a sustainable replacement for chemical surfactants? Biotechnol Lett 34:1597-1605. https://doi.org/10.1007/s10529-012-0956$\mathrm{x}$

Margesin R, Schinner F (2001) Potential of halotolerant and halophilic microorganisms for biotechnology. Extremophiles 5:73-83

Mata-Sandoval JC, Karns J, Torrents A (2001) Effect of nutritional and environmental conditions on the production and composition of rhamnolipids by $P$. aeruginosa UG2. Microbiol Res 155:249-256. https://doi.org/10.1016/ S0944-5013(01)80001-X

McGenity TJ, Folwell BD, McKew BA, Sanni GO (2012) Marine crude-oil biodegradation: a central role for interspecies interactions. Aquat Biosyst 8:10. https://doi.org/10. 1186/2046-9063-8-10

Mnif S, Chamkha M, Sayadi S (2009) Isolation and characterization of Halomonas sp. strain C2SS100, a hydrocarbondegrading bacterium under hypersaline conditions. J Appl Microbiol 107:785-794. https://doi.org/10.1111/j.13652672.2009.04251.x

Mukherjee S, Das P, Sivapathasekaran C, Sen R (2009) Antimicrobial biosurfactants from marine Bacillus circulans: extracellular synthesis and purification. Lett Appl Microbiol 48:281-288. https://doi.org/10.1111/j.1472765X.2008.02485.x

Nakar D, Gutnick DL (2001) Analysis of the wee gene cluster responsible for the biosynthesis of the polymeric bioemulsifier from the oil-degrading strain Acinetobacter 
lwoffii RAG-1. Microbiology 147:1937-1946. https://doi. org/10.1099/00221287-147-7-1937

Ortega-de la Rosa ND, Vázquez-Vázquez JL, Huerta-Ochoa S, Gimeno M, Gutiérrez-Rojas M (2018) Stable bioemulsifiers are produced by Acinetobacter bouvetii UAM25 growing in different carbon sources. Bioprocess Biosyst Eng. https://doi.org/10.1007/s00449-018-1920-5

Pal A, Paul AK (2008) Microbial extracellular polymeric substances: central elements in heavy metal bioremediation Indian. J Microbiol 48:49-64. https://doi.org/10.1007/ s12088-008-0006-5

Pepi M, Cesaro A, Liut G, Baldi F (2005) An antarctic psychrotrophic bacterium Halomonas sp. ANT-3b, growing on $n$-hexadecane, produces a new emulsyfying glycolipid. FEMS Microbiol Ecol 53:157-166. https://doi.org/10. 1016/j.femsec.2004.09.013

Perfumo A, Smyth TJP, Marchant R, Banat IM (2010) Production and roles of biosurfactants and bioemulsifiers in accessing hydrophobic substrates. In: Timmis KN (ed) Handbook of hydrocarbon and lipid microbiology. Springer, Heidelberg, pp 1501-1512. https://doi.org/10. 1007/978-3-540-77587-4_103

Perfumo A, Rudden M, Smyth TJ, Marchant R, Stevenson PS, Parry NJ, Banat IM (2013) Rhamnolipids are conserved biosurfactants molecules: implications for their biotechnological potential. Appl Microbiol Biotechnol 97:7297-7306. https://doi.org/10.1007/s00253-013-4876$\mathrm{z}$

Perfumo A, Banat IM, Marchant R (2018) Going green and cold: biosurfactants from low-temperature environments to biotechnology applications. Trends Biotechnol 36:277-289. https://doi.org/10.1016/j.tibtech.2017.10.016

Plaza GA, Chojniak J, Banat IM (2014) Biosurfactant mediated biosynthesis of selected metallic nanoparticles. Int J Mol Sci 15:13720-13737. https://doi.org/10.3390/ ijms 150813720

Raddadi N, Giacomucci L, Totaro G, Fava F (2017) Marinobacter sp. from marine sediments produce highly stable surface-active agents for combatting marine oil spills. Microb Cell Fact 16:186. https://doi.org/10.1186/ s12934-017-0797-3

Reddy MS, Naresh B, Leela T, Prashanthi M, Madhusudhan N, Dhanasri G, Devi P (2010) Biodegradation of phenanthrene with biosurfactant production by a new strain of Brevibacillus sp. Bioresour Technol 101:7980-7983. https://doi.org/10.1016/j.biortech.2010.04.054

Reisfeld A, Rosenberg E, Gutnick D (1972) Microbial degradation of crude oil: factors affecting the dispersion in sea water by mixed and pure cultures. Appl Microbiol 24:363-368

Roling WF, Milner MG, Jones DM, Lee K, Daniel F, Swannell RJ, Head IM (2002) Robust hydrocarbon degradation and dynamics of bacterial communities during nutrient-enhanced oil spill bioremediation. Appl Environ Microbiol 68:5537-5548

Roling WF, Milner MG, Jones DM, Fratepietro F, Swannell RP, Daniel F, Head IM (2004) Bacterial community dynamics and hydrocarbon degradation during a field-scale evaluation of bioremediation on a mudflat beach contaminated with buried oil. Appl Environ Microbiol 70:2603-2613
Rosenberg E, Zuckerberg A, Rubinovitz C, Gutnick DL (1979) Emulsifier of Arthrobacter RAG-1: isolation and emulsifying properties. Appl Environ Microbiol 37:402-408

Roy S, Chandni S, Das I, Karthik L, Kumar G, Bhaskara Rao KV (2015) Aquatic model for engine oil degradation by rhamnolipid producing Nocardiopsis VITSISB 3. Biotech 5:153-164. https://doi.org/10.1007/s13205-014-0199-8

Rudden M, Tsaousi K, Marchant R, Banat IM, Smyth TJ (2015) Development and validation of an ultra-performance liquid chromatography tandem mass spectrometry (UPLC-MS/ MS) method for the quantitative determination of rhamnolipid congeners. Appl Microbiol Biotechnol 99:9189. https://doi.org/10.1007/s00253-015-6968-4

Salata O (2004) Applications of nanoparticles in biology and medicine. J Nanobiotechnol 2:3. https://doi.org/10.1186/ 1477-3155-2-3

Santos DKF, Resende AHM, De Almeida DG, Da Silva RDFS, Dufino RD, Launa JM, Banat IM, Sarubbo LA (2017) Candida lipolytica UCP0988 biosurfactant: potential as a bioremediation agent and in formulating a commercial related product. Front Microbiol 8:767. https://doi.org/10. 3389/fmicb.2017.00767

Schneiker S, dos Santos VAP, Bartel D et al (2006) Genome sequence of the ubiquitous hydrocarbon-degrading marine bacterium Alcanivorax borkumensis. Nat Biotechnol 24:997-1004. https://doi.org/10.1038/nbt1232

Scoma A, Barbato M, Borin S, Daffonchio D, Boon N (2016a) An impaired metabolic response to hydrostatic pressure explains Alcanivorax borkumensis recorded distribution in the deep marine water column. Sci Rep 6:31316. https:// doi.org/10.1038/srep31316

Scoma A, Barbato M, Hernandez-Sanabria E, Mapelli F, Daffonchio D, Borin S, Boon N (2016b) Microbial oil-degradation under mild hydrostatic pressure (10 MPa): which pathways are impacted in piezosensitive hydrocarbonoclastic bacteria? Sci Rep 6:23526. https://doi.org/10.1038/ srep23526

Sivapathasekaran C, Mukherjee S, Samanta R, Sen R (2009) High-performance liquid chromatography purification of biosurfactant isoforms produced by a marine bacterium. Anal Bioanal Chem 395:845-854. https://doi.org/10.1007/ s00216-009-3023-2

Sivapathasekaran C, Das P, Mukherjee S, Saravanakumar J, Mandal M, Sen R (2010) Marine bacterium derived lipopeptides: characterization and cytotoxic activity against cancer cell lines. Int J Pept Res Ther 16:215-222. https://doi.org/10.1007/s10989-010-9212-1

Smyth TJP, Perfumo A, Marchant R, Banat IM (2010) Isolation and analysis of low molecular weight microbial glycolipids. In: Timmis KN (ed) Handbook of hydrocarbon and lipid microbiology. Springer, Berlin, pp 3705-3723. https://doi.org/10.1007/978-3-540-77587-4_291

Stein JL, Marsh TL, Wu KY, Shizuya H, DeLong EF (1996) Characterization of uncultivated prokaryotes: isolation and analysis of a 40-kilobase-pair genome fragment from a planktonic marine archaeon. J Bacteriol 178:591-599

Swaathy S, Kavitha V, Pravin AS, Mandal AB, Gnanamani A (2014) Microbial surfactant mediated degradation of anthracene in aqueous phase by marine Bacillus licheniformis MTCC 5514. Biotechnol Rep 4:161-170. https:// doi.org/10.1016/j.btre.2014.10.004 
Syutsubo K, Kishira H, Harayama S (2001) Development of specific oligonucleotide probes for the identification and in situ detection of hydrocarbon-degrading Alcanivorax strains. Environ Microbiol 3:371-379

Tan D, Xue YS, Aibaidula G, Chen GQ (2011) Unsterile and continuous production of polyhydroxybutyrate by Halomonas TD01. Bioresour Technol 102:8130-8136. https:// doi.org/10.1016/j.biortech.2011.05.068

Thavasi R, Jayalakshmi S, Balasubramanian T, Banat IM (2007) Biosurfactant production by Corynebacterium kutscheri from waste motor lubricant oil and peanut oil cake. Lett Appl Microbiol 45:686-691. https://doi.org/10.1111/j. 1472-765X.2007.02256.x

Thavasi R, Subramanyam Nambaru VR, Jayalakshmi S, Balasubramanian T, Banat IM (2009) Biosurfactant production by Azotobacter chroococcum isolated from the marine environment. Mar Biotechnol 11:551-556. https://doi.org/ 10.1007/s10126-008-9162-1

Thavasi R, Jayalakshmi S, Banat IM (2011) Effect of biosurfactant and fertilizer on biodegradation of crude oil by marine isolates of Bacillus megaterium, Corynebacterium kutscheri and Pseudomonas aeruginosa. Bioresour Technol 102:772-778. https://doi.org/10.1016/j.biortech.2010. 08.099

Thavasi R, Jayalakshmi S, Banat IM (2014) Biosurfactants and bioemulsifiers from marine sources. In: Mulligan $\mathrm{CN}$, Sharma SK, Mudhoo A (eds) Biosurfactants. HardbackCRC Press, Boca Raton, pp 125-146. https://doi.org/10. 1201/b16383-6

Toren A, Orr E, Paitan Y, Ron EZ, Rosenberg E (2002) The active component of the bioemulsifier alasan from Acinetobacter radioresistens KA53 is an OmpA-like protein. J Bacteriol 184:165-170

Twigg MS, Tripathi L, Zompra A, Salek K, Irorere VU, Gutierrez T, Spyroulias GA, Marchant R, Banat IM (2018) Identification and characterisation of short chain rhamnolipid production in a previously uninvestigated, nonpathogenic marine Pseudomonad. Appl Microbiol Biotechnol. https://doi.org/10.1007/s00253-018-9202-3

Uzoigwe C, Burgess JG, Ennis CJ, Rahman PK (2015) Bioemulsifiers are not biosurfactants and require different screening approaches. Front Microbiol 6:245. https://doi. org/10.3389/fmicb.2015.00245
Vater J, Kablitz B, Wilde C, Franke P, Mehta N, Cameotra SS (2002) Matrix-assisted laser desorption ionization-time of flight mass spectrometry of lipopeptide biosurfactants in whole cells and culture filtrates of Bacillus subtilis $\mathrm{C}-1$ isolated from petroleum sludge. Appl Environ Microbiol 68:6210-6219

Vecino X, Cruz JM, Moldes AB, Rodrigues LR (2017) Biosurfactants in cosmetic formulations: trends and challenges. Crit Rev Biotechnol 37:911-923. https://doi.org/ 10.1080/07388551.2016.1269053

Vilela WF, Fonseca SG, Fantinatti-Garboggini F, Oliveira VM, Nitschke M (2014) Production and properties of a surfaceactive lipopeptide produced by a new marine Brevibacterium luteolum strain. Appl Biochem Biotechnol 174:2245-2256. https://doi.org/10.1007/s12010-0141208-4

Walsh F, Duffy B (2013) The culturable soil antibiotic resistome: a community of multi-drug resistant bacteria. PLoS ONE 8:e65567. https://doi.org/10.1371/journal.pone. 0065567

Wang Q, Fang X, Bai B, Liang X, Shuler PJ, Goddard WA 3rd, Tang Y (2007) Engineering bacteria for production of rhamnolipid as an agent for enhanced oil recovery. Biotechnol Bioeng 98:842-853. https://doi.org/10.1002/ bit. 21462

Yakimov MM, Golyshin PN, Lang S, Moore ER, Abraham WR, Lunsdorf H, Timmis KN (1998) Alcanivorax borkumensis gen. nov., sp. nov., a new, hydrocarbon-degrading and surfactant-producing marine bacterium. Int J Syst Bacteriol 48(Pt 2):339-348. https://doi.org/10.1099/00207713-48-2339

Zenati B et al (2018) A non-toxic microbial surfactant from Marinobacter hydrocarbonoclasticus SdK644 for crude oil solubilization enhancement. Ecotoxicol Environ Saf 154:100-107. https://doi.org/10.1016/j.ecoenv.2018.02. 032

Zhu Z, Zhang B, Chen B, Cai Q, Lin W (2016) Biosurfactant production by marine-originated bacteria Bacillus Subtilis and its application for crude oil removal. Water Air Soil Pollut 227:328. https://doi.org/10.1007/s11270-016-3012-y 